\title{
Can Soy Diet be Protective in Severe and Diffuse Traumatic Brain Injury?
}

Zahra Soltani $^{1}$, Mohammad Khaksari ${ }^{2}$, Sedigheh Amiresmaili ${ }^{3}$, Vida Naderi ${ }^{2}$, Elham Jafari ${ }^{5}$ and Nader Shahrokhi ${ }^{1}$

1Physiology Research Center, Institute of Neuropharmacology, Kerman University of Medical Sciences, Kerman, Iran

2Neuroscience Research Center, Institute of Neuropharmacology, Kerman University of Medical Sciences, Kerman, Iran

3Department of Physiology, Bam University of Medical Sciences, Kerman, Iran

4Department of Pathology, Kerman Hospital of Shahid Bahonar, Kerman, Iran

*Corresponding author: Mohammad Khaksari, Neuroscience Research Center, Institute of Neuropharmacology, Kerman University of Medical Sciences, Kerman, Iran, Tel: +9834 33220081; Fax: +9834 33220081; E-mail: khaksar38@yahoo.co.uk

Received date: Sep 24, 2014, Accepted date: Nov 17, 2014, Published date: Nov 21, 2014

Copyright: (C) 2014 Soltani Z, et al. This is an open-access article distributed under the terms of the Creative Commons Attribution License, which permits unrestricted use, distribution, and reproduction in any medium, provided the original author and source are credited.

\begin{abstract}
Our previous studies have demonstrated that estrogen is protective in traumatic brain injury (TBI). However, concerns about negative consequences of estrogen therapy have led to find other strategies to obtain estrogen's benefits in the brain, including the use of a soy diet. This study was designed to determine whether a soy diet is protective in TBI. The male Albino N-Mary rats received either a soy- free diet (SFD) or soy diet (SD) from weaning to adulthood. The SFD and SD rats were separately divided to two groups of sham and TBI ( $n=18$ in each group). The diffuse and severe brain injury was induced by Marmarou method. The disruption of Blood brain- barrier (BBB) was evaluated $48 \mathrm{~h}$ post- TBI. The intracranial pressure (ICP), the neurologic outcome, and the beam-walk task (WB) were determined before trauma, on trauma day (D0), and first (D1) and second (D2) days post- TBI. Evans blue dye was significantly high in the SFD + TBI group vs. other groups. The ICP was significantly high in the SFD + TBI group in all times evaluated, and in the SD + TBI group on D1 and D2, however lower than that in the former group. The neurologic outcome score was significantly low in the SFD + TBI group vs. the sham groups in all times. Also the traversal time in WB task was significantly high in the SFD + TBI group not the SD + TBI group, vs. the sham groups in all times, however significant difference of distance traveled was shown only on trauma day. The results of this study demonstrate that soy diet can prevent the disruption of BBB, and attenuate the elevation of ICP, and the disturbance of vestibulomotor and neurologic performance in TBI.
\end{abstract}

Keywords Brain injury; Intracranial pressure; Blood- brain barrier Neurologic outcome

\section{Abbreviations:}

BBB: Blood brain- barrier; BW: Beam-walk; EB: Evans blue; ER: Estrogen receptor; HIF1a: Hypoxia-inducible factor 1-alpha; ICP: Intracranial pressure; SD: Soy diet; SFD: Soy- free diet; TBI: Traumatic brain injury; VCS: Veterinary coma scale; VEGF: Vascular endothelial growth factor

\section{Introduction}

Traumatic brain injury (TBI) is a major cause of death in the worldwide [1]. TBI is caused by both primary and secondary injuries. The primary injury results from the forces at the time of trauma and is irreversible. The secondary mechanisms initiated at the time of trauma have an important role in the progression of brain damage [2]. The brain edema and the increased intracranial pressure (ICP) are the immediate outcomes of TBI leading to early death [3].

In vivo and in vitro studies have demonstrated the neuro-protective effect of estrogens against variety of insults. In rodents, estrogen reduces injury caused by focal cerebral ischemia [4], global ischemia [5], and cerebral trauma [6,7]. However, the use of estrogen as hormone therapy is controversial in humans because of the deleterious side- effects of hormone replacement therapy, such as the increased cancer and stroke risk $[8,9]$.
There is growing evidence that the consumption of some plants known as the phytoestrogens, could be efficient to prevent or treat several dysfunctions and diseases including stroke, and neurodegeneration [10]. Phytoestrogens present in fruits, vegetables, and whole grains commonly consumed by humans [11]. The chemical structure of phytoestrogen is similar to the mammalian estrogen; estradiol, and this sex steroid hormone binds to estrogen receptors (ER) alpha and beta for mediation of effects $[12,13]$. It has been suggested soy dietary as the most promising source of Phytoestrogens [14].

Recent studies suggest that the dietary soy $[15,16]$ or the administration of isoflavone phytoestrogens of soy (genistein and daidzein) [17] may have protective effects in the brain, like estrogen. Genistein and daidzein of soy have been suggested as the selective ER modulators [18].

The neuroprotective effect of soy diet has been demonstrated in animal stroke $[19,20]$. The animal experiments have reported the neuroprotective effect of phytoestrogens, to prevent oxidative stressinduced degenerative changes in the neurons [21]. Soy phytoestrogens are able to inhibit the inflammation, and immune response [22].

Taken, estrogen as a protective agent has suggested in the neurodegenerative disorders [6,7], and using dietary soy and its isoflavones as alternatives to hormone replacement therapy is increasing [23]. Therefore we hypothesized that soy diet as an alternative of hormone therapy would reduce the extent of brain injury in diffuse and severe TBI. We evaluated the effect of soy diet on blood 
Page 2 of 7

brain barrier (BBB) permeability, intracranial pressure (ICP), neurologic outcome, and vestibule motor performance in male TBIinduced rats.

\section{Methods}

This study was executed in accordance with RIGOR guidelines, disclosures, blinding and randomization [24]. The surgical, and evaluation of BBBpermeability and neurologic outcome procedures have been described in detail in our previous publications $[25,26]$.

\section{Animals and pre-surgical procedures}

The study was performed in accordance with protocol approved by the ethical committee (No EC/KNRC/93-116) in Kerman University of Medical Sciences, in accordance with internationally approved principles for the animal use and care, as found in the European community guidelines (EU Directive of 2010; 2010/63/EU) or US guidelines (NIH publication \#85-23, revised in 1985). The male Albino N-Mari rats were purchased just after weaning (3- weeks after birth), and were randomly received either a soy- free diet or soy diet (according to WUFFF DA software; prepared by Javanehkhorasan Company, Mashhad, Iran) (Table 1) referred to here as SFD, and SD respectively. The SFD and SD rats were housed in the separate steelwire cages and allowed to grow for 15-17 additional weeks in a temperature $\left(21 \pm 1^{\circ} \mathrm{C}\right.$ ) and light (on 7:00 a.m. to 7:00 p.m.) controlled environment with food and water available ad libitum. After this time, the SFD and SD rats were randomly divided to sham (control) and TBI groups. Therefore the study groups were: SFD + sham, SFD + TBI, SD + sham, and SD + TBI. All parameters were measured by experimenter that was blind for studied groups (Table 1).

\begin{tabular}{|c|c|c|c|}
\hline $\begin{array}{l}\text { Soy- Free Diet } \\
(\%)\end{array}$ & Soy Diet (\%) & Units & $\begin{array}{l}\text { Nutrient } \\
\text { Composition }\end{array}$ \\
\hline 86.84 & 88.08 & $\%$ & Dry Matter \\
\hline 2.90 & 2.90 & $\mathrm{Kcal} / \mathrm{g}$ & $\begin{array}{l}\text { Metabolozable } \\
\text { Energy }\end{array}$ \\
\hline 23.14 & 23.18 & $\%$ & Protein \\
\hline 4.11 & 2.68 & $\%$ & Ether Extract \\
\hline 1.56 & 2 & $\%$ & Linoleic Acid \\
\hline 2.99 & 3.60 & $\%$ & Crude Fiber \\
\hline 0.86 & 1.19 & $\%$ & Calcium \\
\hline 0.88 & 0.85 & $\%$ & Total Phosphorus \\
\hline 0.52 & 0.50 & $\%$ & Avail. Phosphorus \\
\hline 0.08 & 1.40 & & Ca: $P=2$ \\
\hline 0.63 & 0.63 & $\%$ & Chlorine \\
\hline 635.28 & 630.14 & $\mathrm{mg} / \mathrm{kg}$ & Manganese \\
\hline 0.22 & 0.23 & $\%$ & Sodium \\
\hline 542.11 & 517.17 & $\mathrm{mg} / \mathrm{kg}$ & Zinc \\
\hline 26.17 & 13.34 & $\mathrm{mg} / \mathrm{g}$ & Choline \\
\hline 1.36 & 6.77 & $\mathrm{mg} / \mathrm{kg}$ & Folic Acid \\
\hline
\end{tabular}

\begin{tabular}{|l|l|l|l|}
\hline 1.12 & 1.39 & $\%$ & Arginine \\
\hline 1.02 & 0.86 & $\%$ & Glycine \\
\hline 0.89 & 1.03 & $\%$ & Serine \\
\hline 1.91 & 2.19 & $\%$ & $\begin{array}{l}\text { Glycine and } \\
\text { Serine }\end{array}$ \\
\hline 0.49 & 0.55 & $\%$ & Histidine \\
\hline 0.86 & 0.86 & $\%$ & Isoleucine \\
\hline 2.13 & 1.78 & $\%$ & Leucine \\
\hline 2.31 & 2.23 & $\%$ & Lysine \\
\hline 1.87 & 1.50 & $\%$ & Methionine \\
\hline 0.32 & 0.35 & $\%$ & Cysteine \\
\hline 2.20 & 1.85 & $\%$ & TSAA \\
\hline 0.95 & 0.99 & $\%$ & Phenylalanine \\
\hline 0.76 & 0.8 & $\%$ & Tyrosine \\
\hline 1.71 & 1.77 & $\%$ & TAAA \\
\hline 0.76 & 0.77 & $\%$ & Threonine \\
\hline 0.20 & 0.28 & $\%$ & Tryptophan \\
\hline 1.02 & 0.97 & $\%$ & Valine \\
\hline
\end{tabular}

Table 1: Diets compositions; The ingredients list (first six) for the soy diet: soybean, corn and wheat middling. The ingredients list (first six) for the soy- free diet: corn, wheat, fish meal and wheat middling.

\section{Surgery (induction of TBI)}

All animals were intubated before surgery. In the TBI groups, diffuse TBI was induced by Marmarou method using a TBI induction device (made by Dept. of Physiology, Kerman University of Medical Sciences). The severe TBI was induced using a weight $450 \mathrm{~g}$. TBI was induced as we have previously described [25]. In the sham groups, all stages of induction of TBI were performed except dropping weight on the head.

\section{Determination of BBB permeability}

The permeability of BBB was determined by measuring the brain leakage of Evans blue (EB) dye injected, using the absorbance of Evans blue dye of supernatant at $610 \mathrm{~nm}, 48 \mathrm{~h}$ post- trauma as previously described [25]. The amount of dye leakage was quantified as micrograms per gram brain tissue.

\section{Measurement of ICP}

The animal head was fixed in a stereotaxic instrument, as the head at midsagital plane, and the anterior- posterior point at about midpoint between the occipital crest and the lambda suture was located. A 20- gauge needle connected to a pressure transducer using the polyethylene short tube, was joined to a recording system (AD Instruments, Australia) and inserted into the cisterna magna. There was an initial increase then a sudden decrease of resistance due to needle insertion to dura mater and cistern magna respectively, during 
insertion of needle [27]. ICP was recorded before trauma, on trauma day (D0), and first (D1) and second (D2) days post- TBI.

\section{Evaluation of neurological outcomes}

As we described before the neurological outcomes were assessed according to the motor score of veterinary coma scale (VCS) and expressed the range from 1 to 8 [26,28]. Higher scores indicate better neurological outcomes, and lower ones indicate worse neurological outcomes. Theresults were evaluated before trauma, and on D0, D1 and D2 post-TBI.

\section{Evaluation of vestibulomotor function}

The task of beam-walk (BW) is to assess the finer components of vestibulomotor function and coordination. The modified BW task was devised by Feeney and colleagues [29], consist of training rats using a negative-reinforcement paradigm to escape the bright light and white noise by traversing an elevated narrow beam $(2.5 \times 100 \mathrm{~cm})$ and entering a dark goal box located on the opposite end (made by Dept. of Physiology, Kerman University of Medical Sciences). The task of BW was assessed by recording the time elapsed to beam as well as the distance traveled. The scoring criterion for distance traveled is based on a rating scale from 0 to 5 , where 0 indicates inability to move beyond the starting point, 1-4 corresponds to distal segments of 20 , 40,60 , or $80 \mathrm{~cm}$ from the starting point, respectively, and 5 indicates the traveled entire length of the beam $(100 \mathrm{~cm})$. Rats were trained prior to TBI or sham surgery to perform the task without error (i.e., traverse the beam under $5 \mathrm{~s}$ ). Task of BW was assessed before trauma, and on D0, D1 and D2 post- TBI that consisted of three trials for any time evaluated [30]. Data for each time were the mean of three trials. Data were recorded using a camera and software (video tracking, Borjesanat Company, Tehran, Iran).

\section{Statistical Analysis}

Data were presented as mean \pm SEM. The normality of data was checked using the Shapiro Wilk's W test. Because of interaction between the groups and times of evaluation of ICP, and vestibulomotor and neurological outcomes, the comparison of data in each time was analyzed using one-way analysis of variance (ANOVA), the same as the permeability of BBB. Tukey's test was used for post hoc analysis except VCS that used Dunnett's T3 test. The level of significance was considered at $\mathrm{p}<0.05$.

\section{Results}

\section{BBB permeability: EB dye content of brain}

The brain content of EB dye of different groups is shown in Figure 1. The BBB permeability in the SFD + TBI rats $(33.08 \pm 8.64 \mu \mathrm{g} / \mathrm{g}$ tissue) was significantly higher than that in the SFD + sham $(\mathrm{p}<$ $0.001)$, SD + sham $(\mathrm{p}<0.01)$, and SD + TBI $(\mathrm{p}<0.05)$ rats, 48 h postTBI. But the permeability of $\mathrm{BBB}$ was not significantly different between the SD + TBI group and the sham group. The content of brain EB dye was not significantly different between SFD + sham rats and $\mathrm{SD}+$ sham rats.

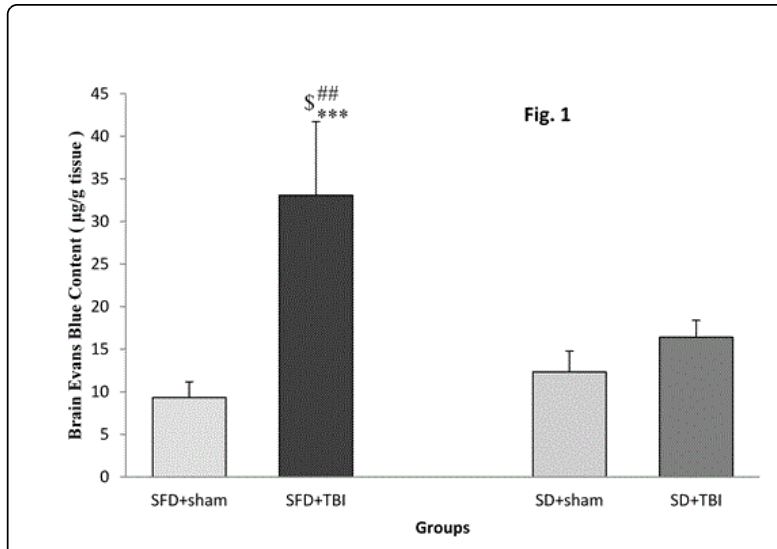

Figure 1: The effect of dietary soy on the permeability of bloodbrain barrier determined by the brain leakage of Evans blue dye in rats with severe traumatic brain injury (TBI), $48 \mathrm{~h}$ post- trauma $(\mathrm{n}=$ 6 in each group). Data are presented as mean \pm SEM. ${ }^{* * *} \mathrm{P}<0.001$ : significant difference of SFD + TBI group with SFD + sham group. \#\# $\mathrm{P}<0.01$ : significant difference of SFD + TBI group with SD + sham group. ${ }^{\$} \mathrm{P}<0.05$ : significant difference of $\mathrm{SFD}+\mathrm{TBI}$ group with SD + TBI group. SFD: soy- free diet; SD: soy diet.

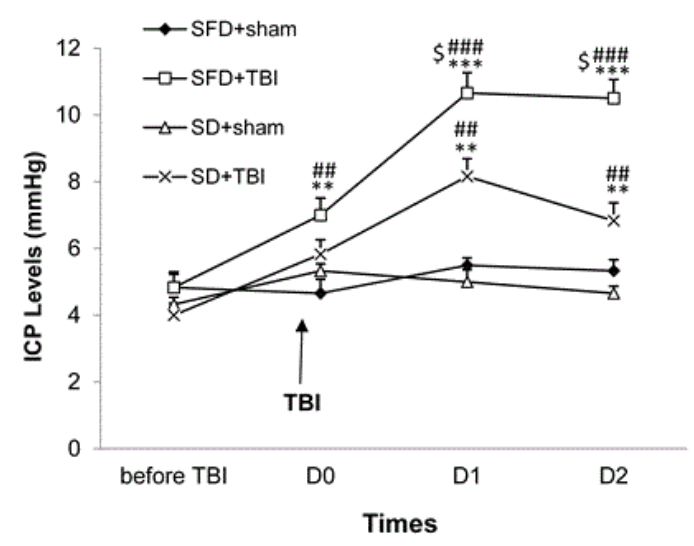

Figure 2: The effect of dietary soy on the intracranial pressure in rats with severe traumatic brain injury (TBI), before trauma, on trauma day (D0), and first (D1) and second (D2) days post- TBI $(\mathrm{n}=6$ in each group). Data are presented as mean \pm SEM. ${ }^{* * *} \mathrm{P}<0.001$ : significant difference of SFD + TBI group with SFD + sham group on $\mathrm{D} 1$ and $\mathrm{D} 2$. ${ }^{\# \# \#} \mathrm{P}<0.001$ : significant difference of SFD + TBI group with SD + sham group on D1 and D2. ${ }^{* *} \mathrm{P}<0.01$ : significant difference of SFD + TBI group with SFD + sham group on D0, SD + TBI group with SFD + sham group on D1 and D2. ${ }^{\# \#} \mathrm{P}<0.01$ : significant difference of SFD + TBI group with $\mathrm{SD}+$ sham group on $\mathrm{D} 0, \mathrm{SD}+\mathrm{TBI}$ group with $\mathrm{SD}+$ sham group on $\mathrm{D} 1$ and D2. ${ }^{\$} \mathrm{P}<0.05$ : significant difference of SFD + TBI group with SD $+\mathrm{TBI}$ group on D1 and D2. SFD: soy- free diet; SD: soy diet. 


\section{ICP}

The measured ICP of the different groups, before trauma, and on D0, D1 and D2, is shown in Figure 2. Before trauma, ICP was not statistically different among the studied groups. On D0, ICP increased in the SFD + TBI group $(7 \pm 0.51 \mathrm{mmHg})$ compared with the sham ( $\mathrm{p}$ $<0.01)$ group. On D1 and D2, ICP in the SFD + TBI rats $(10.66 \pm 0.61$ $\mathrm{mmHg} ; 10.5 \pm 0.56 \mathrm{mmHg}$ respectively) was significantly higher than that in the sham $(\mathrm{p}<0.001)$ and SD + TBI $(\mathrm{p}<0.05)$ rats. On D1 and $\mathrm{D} 2$, ICP in the SD + TBI group $(8.16 \pm 0.43 \mathrm{mmHg} ; 6.83 \pm 0.54 \mathrm{mmHg}$ respectively) was significantly higher than that in the sham groups ( $\mathrm{p}<$ 0.01 ), although there was no that on D0. The level of ICP was not significantly different between SFD + sham rats and SD + sham rats in each time evaluated.

\section{Neurologic outcome: motor score of VCS}

The evaluated neurological scores of different groups, before trauma, and on D0, D1 and D2, is shown in Figure 3. Before trauma, the score was not statistically different among the studied groups. On D0, the score reduced in the SFD + TBI group $(2.67 \pm 0.21)$ compared with that in the sham $(\mathrm{p}<0.01)$ groups. On D1 and D2, the score in the SFD + TBI rats $(6.33 \pm 0.21 ; 7.17 \pm 0.16$ respectively $)$ was significantly lower than that in the sham rats $(\mathrm{p}<0.01 ; \mathrm{p}<0.05$ respectively). The score was not significantly different between the SD + TBI group and the other groups on D0, D1 and D2. The neurologic score was not significantly different between SFD + sham rats and SD + sham rats in each time evaluated.

\section{Vestibulomotor function: BW (traversal time)}

The defined traversal time of BW task of different groups, before trauma, and on D0, D1 and D2, is shown in Figure 4. Before trauma, the time showed no statistically difference among the studied groups as all rats reached the goal box in approximately $5 \mathrm{~s}$. In all times after trauma, the time in the SFD + TBI group no SD + TBI group, was significantly higher than that in the sham groups $(\mathrm{p}<0.05)$. The time in the SD + TBI $(5.66 \pm 0.56 \mathrm{~s})$ rats was significantly lower than that in the SFD +TBI $(10.94 \pm 1.08 \mathrm{~s})$ rats on D2 $(\mathrm{p}<0.05)$. The traversal time of BW task was not significantly different between SFD + sham rats and $\mathrm{SD}+$ sham rats in each time evaluated.

\section{Vestibulomotor function: BW (distance traveled)}

The defined score of distance traveled of BW task of different groups, before trauma, and on D0, D1 and D2, is shown in Figure 5. Before trauma, significant difference of the score was not observed among the groups as all rats traversed the entire length of beam for maximum score of 5 . The score in the SFD + TBI group $(2.68 \pm 0.33)$ was significantly lower than that in the sham groups $(\mathrm{p}<0.01)$ only on D0 not D1 and D2. There is no significant difference in the score between the SD + TBI group and the other groups on D0, D1 and D2. The score of distance traveled of BW task was not significantly different between SFD + sham rats and SD + sham rats in each time evaluated.

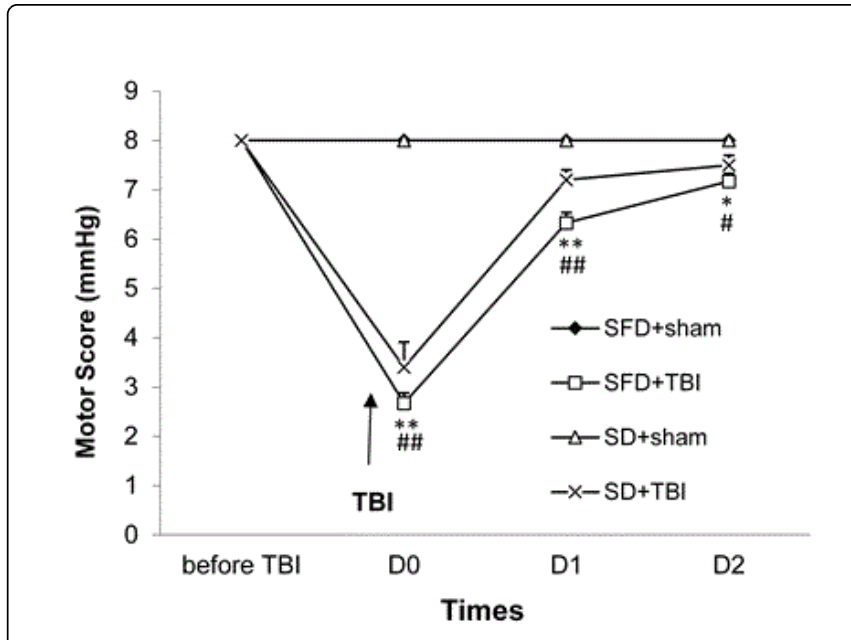

Figure 3: The effect of dietary soy on the neurologic outcome using motor score of veterinary coma scale in rats with severe traumatic brain injury (TBI), before trauma, on trauma day (D0), and first (D1) and second (D2) days post-trauma ( $\mathrm{n}=6$ in each group). Data are presented as mean \pm SEM. ${ }^{* *} \mathrm{P}<0.01$ : significant difference of SFD + TBI group with SFD + sham group on D0 and D1. ${ }^{\# \#} \mathrm{P}<0.01$ : significant difference of SFD + TBI group with $\mathrm{SD}+$ sham group on D0 and D1. ${ }^{*} \mathrm{P}<0.05$ : significant difference of SFD + TBI group with SFD + sham group on $\mathrm{D} 2 .{ }^{\#} \mathrm{P}<0.05$ : significant difference of SFD + TBI group with SD + sham group on D2. SFD: soy- free diet; SD: soy diet.

\section{Discussion}

The present study for the first time determined the effect of soy diet in an animal model of diffuse TBI. In this survey, in TBI- induced animals, the reduction of BBB permeability and ICP, and the improvement of neurologic and vestibulomotor performance was shown in SD animals compared with SFD animals.

Soy phytoestrogens have been introduced as a safe alternative to hormonal replacement therapy for preventing or suppressing neurodegenerative disorders [31] because of deleterious side-effects of hormone replacement therapy $[8,9]$. The studies suggest that dietary soy is neuroprotective in the experimental cerebral ischemia $[19,20]$. The isoflavones of soy (genistein and daidzein) have been postulated with the neuroprotective actions. Genistein and daidzein isoflavones, can bind to ERs and mimic some of estrogen's effects [32]. Damage of central nervous system causes neuro-inflammatory responses including, the disruption of blood-brain barrier [33], the elevation of ICP, [7] and the acute increase of pro- inflammatory cytokines [34].

Data from a study have indicated the maximum of $\mathrm{BBB}$ permeability at $48 \mathrm{~h}$ after brain injury [35]. In the present study, BBB permeability (vasogenic edema) was evaluated at $48 \mathrm{~h}$ post- trauma. The amount of disruption of BBB was shown $71 \%$, but soy diet prevented this disruption. The reported disruption of BBB at 48 posttrauma is in agreement with results on other studies [36,37]. The protective effect of soy on the permeability of BBB has been shown mediated to the reduction of endothelial hypoxia-inducible factor 1alpha (HIF1a) and vascular endothelial growth factor (VEGF) [38]. It is known that the increasing free radicals has a role in the $\mathrm{BBB}$ 
disruption [39]. It has also been suggested that soy isoflavones, have scavenging function [40]. The disruption of $\mathrm{BBB}$ is also due to development of inflammatory mechanisms [41]. Anti-inflammatory effect of soy isoflavone has been demonstrated [42]. Therefore, dietary soy can probably prevent the formation of brain vasogenic edema, because of its antioxidant and anti-inflammatory effects as well as vascular protective alterations. The controlling of ICP is recommended in TBI patients [43]. In present study, the elevation of ICP was initiated one hour after trauma, and continued for $48 \mathrm{~h}$ consistent with our other studies [25,44].

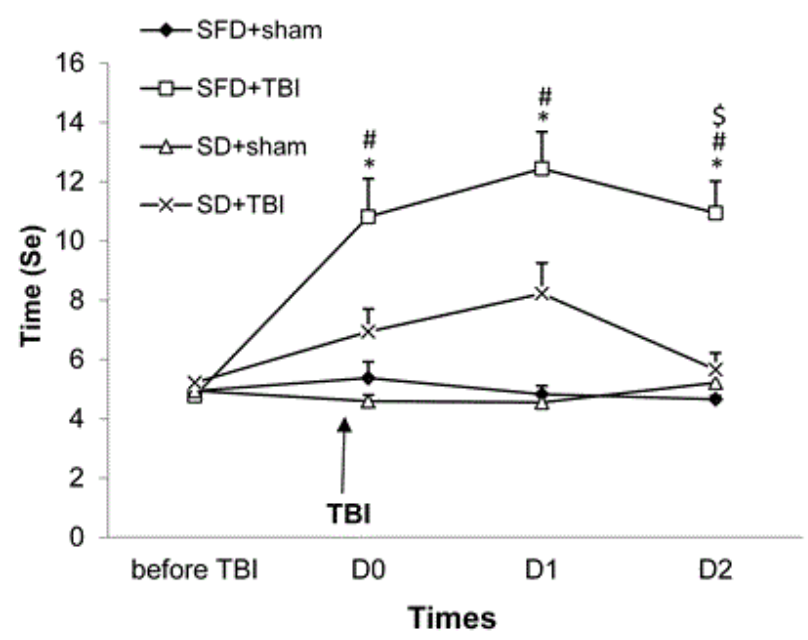

Figure 4: The effect of dietary soy on the time (s) to traverse an elevated narrow beam in rats with severe traumatic brain injury (TBI), before trauma, on trauma day (D0), and first (D1) and second (D2) days post-trauma ( $\mathrm{n}=6$ in each group). Data are presented as mean \pm SEM. ${ }^{*} \mathrm{P}<0.05$ : significant difference of $\mathrm{SFD}+$ TBI group with $\mathrm{SFD}+$ sham group on $\mathrm{D} 0, \mathrm{D} 1$ and $\mathrm{D} 2 .{ }^{*} \mathrm{P}<0.05$ : significant difference of SFD + TBI group with SD + sham group on D0, D1 and D2. ${ }^{\$} \mathrm{P}<0.05$ : significant difference of SFD + TBI group with SD + TBI group on D2. SFD: soy- free diet; SD: soy diet.

The results of our research indicated that soy diet prevented the increase of ICP on trauma day (first hour). Although the increase of ICP was observed on post-trauma days in SD rats, but this increase was lower than that in SFD rats. The later result can exist because low concentration of phytoestrogens might not be adequate to fully activate the neuroprotective pathways [19] for prohibiting ICP elevation on days post- TBI. The causes of the ICP increase in TBI could be hypoxia [45], the reduction of cerebral blood flow [46], cerebral edema [47], ischemic injury, hyper- perfusion in the early stages after TBI [48], changes in the expression of aquaporin-4 [49] and vaso-paralysis, and impaired auto- regulation [50]. It seems that our study is the first to evaluate the effect of soy on ICP. Estrogen prevents ICP elevation after TBI by its antioxidant effect [51]. Since, soy isoflavones have antioxidant effect [52], this effect is supposed as an action mechanism of soy in the prevention of increasing ICP. Prevention of elevation of ICP by soy may be due to the prevention of the vasogenic edema development [53]. The deterioration of neurologic outcome post- trauma was observed on trauma day, and continued until $48 \mathrm{~h}$ post- trauma in our research, consistent with other study [44].

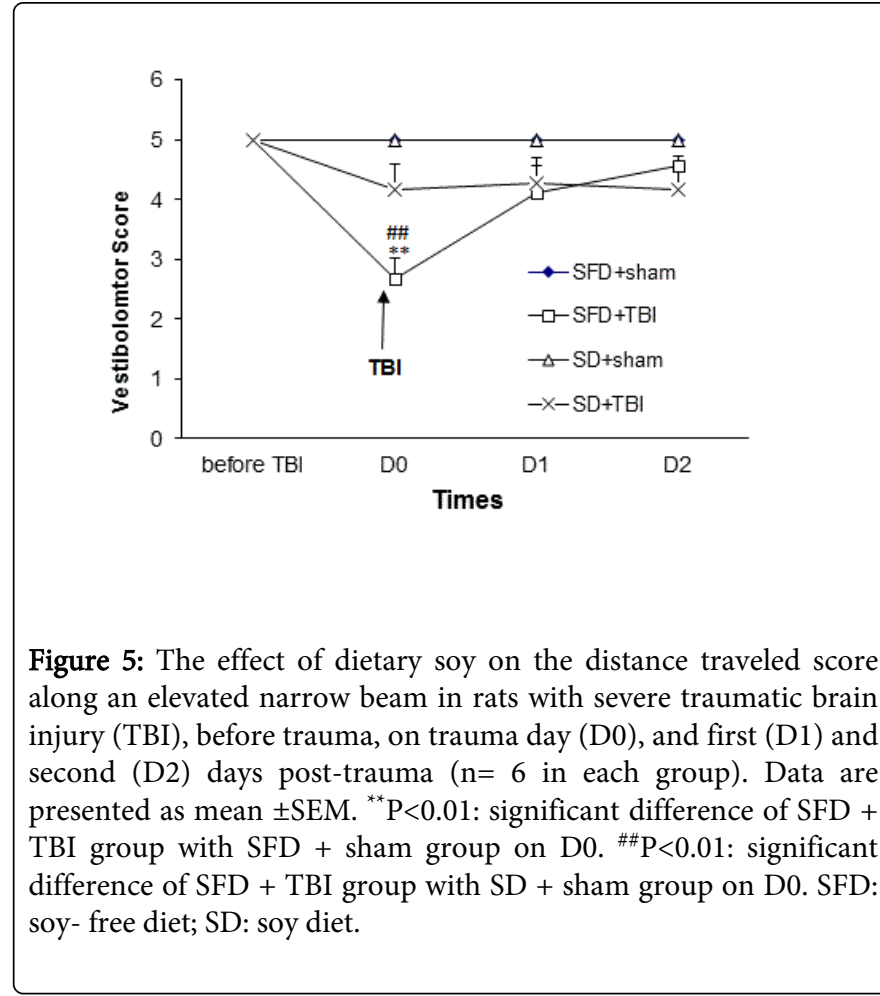

The brain edema is a major cause of the neurological deterioration following TBI [40]. The preventive effect of soy on the neurologic outcome post- trauma was indicated on the trauma day, and days post- TBI. The improvement of neurologic outcome by genistein has been reported in a model of ischemia in mice [54]. The isoflavones of dietary soy have improved stroke outcome in male rats following ischemia [20, 55-57]. The increase in neurologic score can occur through ICP decrease [25,28]. It is assumed that the reduction of ICP might cause a protective mechanism of soy on neurologic outcome. The protective effect of soy on neurologic outcome has not been found in some studies $[19,56,58]$. The methodological, strain, sex, consumption, and injury differences can underlie the discrepancies.

Our findings on the evaluating vestibulomotor function using BW task showed the traversal time increased on trauma day, and continued until $48 \mathrm{~h}$ post- trauma, whereas the score of distance traveled reduced only on the trauma day. These results are in agreement with study performed in rats with diffuse TBI [59]. Soy diet prevented the elevation of traversal time and the reduction of score of distance traveled. The behavioral benefits of soy have been indicated in experimental ischemia in agreement with our results $[28,56]$.The improvement in behavioral function correlates with the significant cortical and hippocampal tissue preservation [42]. The behavioral function has a direct relation with ICP [43]. Therefore the reduction of ICP following the reduction of brain edema may be as one of action probable mechanism(s) of soy in preservation of vestibulomotor task.

The present research demonstrated that soy diet did not change the BBB permeability, ICP levels, neurologic and vestibulomotor outcome in intact rats. Also, the indicated neurologic and vestibulomotor protection by soy diet occurred in the presence of reduced BBB permeability and ICP. It remains to be proved whether the protective effect of dietary soy in TBI can be mimicked by soy supplements or 
individual isoflavones. Also, the molecular mechanisms underlying the neuroprotective effect of soy in TBI must be determined.

The other cellular and molecular mechanisms of neuroprotection by soy can cause through the disruption of beta amyloid, the reduction of caspase-dependent and caspase-independent neuronal apoptosis, the increase of B-cell lymphoma 2 (Bcl2), the activation of PI3K [60], and the prevention of mitochondrial dysfunction [61].

\section{Conclusion}

Our data suggest that, a soy diet attenuates the disruption of BBB and the elevation ICP, and improves the neurologic and vestibulomotor function. Although it must be determined whether these effects work via estrogen receptors, these findings support a role for soy phytoestrogens as neuroprotective agents and possible alternatives to estrogen.

\section{Acknowledgements}

We thanked Dr. Mahmoudi and Mrs. Esmaili in the Departments of Biochemistry and Physiology respectively, Medical School of Afzalipour, Kerman University of Medical Sciences, and Kerman, Iran for providing language. The present study was financially supported by Physiology and Neuroscience research centers of Kerman University of Medical Sciences. We thanked managers of these centers, Prof. Najafipour and Prof. Shaibani.

\section{References}

1. Du AL, Ji TL, Yang B, Cao JF, Zhang XG, et al. (2013) Neuroprotective effect of AG490 in experimental traumatic brain injury of rats. Chin Med J (Engl) 126: 2934-2937.

2. An J, Tzagarakis-Foster C, Scharschmidt TC, Lomri N, Leitman DC (2001) Estrogen receptor beta-selective transcriptional activity and recruitment of coregulators by phytoestrogens. J BiolChem 276: 17808-17814

3. Jayakumar AR, Rao KV, Panickar KS, Moriyama M, Reddy PV, et al. (2008) Trauma-induced cell swelling in cultured astrocytes. J NeuropatholExpNeurol 67: 417-427.

4. Gibson CL, Gray LJ, Murphy SP, Bath PM (2006) Estrogens and experimental ischemic stroke: a systematic review. J Cereb Blood Flow Metab 26: 1103-1113.

5. Jover T, Tanaka H, Calderone A, Oguro K, Bennett MV, et al. (2002) Estrogen protects against global ischemia-induced neuronal death and prevents activation of apoptotic signaling cascades in the hippocampal CA1. The Journal of neuroscience 22: 2115-2124.

6. Khaksari M, Soltani Z, Shahrokhi N, Moshtaghi G and Asadikaram G (2011) The role of estrogen and progesterone, administered alone and in combination, in modulating cytokine concentration following traumatic brain injury. Can J PhysiolPharmacol 89: 31-40.

7. Shahrokhi N, Khaksari M, Soltani Z, Mahmoodi M, Nakhaee N (2010) Effect of sex steroid hormones on brain edema, intracranial pressure, and neurologic outcomes after traumatic brain injury. Can J PhysiolPharmacol 88: 414-421.

8. Brass LM (2004) Hormone replacement therapy and stroke: clinical trials review. Stroke 35: 2644-2647.

9. Wassertheil-Smoller S, Hendrix SL, Limacher M, Heiss G, Kooperberg C, et al. (2003) Effect of estrogen plus progestin on stroke in postmenopausal women: the Women's Health Initiative: a randomized trial. JAMA 289: 2673-2684.

10. Cassidy A (2003) Potential risks and benefits of phytoestrogen-rich diets. Int J VitamNutr Res 73: 120-126.
11. Michel T, Halabalaki M, Skaltsounis AL (2013) New concepts, experimental approaches, and dereplication strategies for the discovery of novel phytoestrogens from natural sources. Planta Med 79: 514-532.

12. Rietjens IM, Sotoca AM, Vervoort J, Louisse J (2013) Mechanisms underlying the dualistic mode of action of major soy isoflavones in relation to cell proliferation and cancer risks. MolNutr Food Res 57: 100-113.

13. Paterni I, Granchi C1, Katzenellenbogen JA2, Minutolo F3 (2014) Estrogen receptors alpha (ERÎ \pm ) and beta $\left(E R \hat{I}^{2}\right)$ : Subtype-selective ligands and clinical potential. Steroids 90C: 13-29.

14. Kronenberg F, Fugh-Berman A (2002) Complementary and alternative medicine for menopausal symptoms: a review of randomized, controlled trials. Ann Intern Med 137: 805-813.

15. Lund TD, West TW, Tian LY, Bu LH, Simmons DL, et al. (2001) Visual spatial memory is enhanced in female rats (but inhibited in males) by dietary soy phytoestrogens. BMC Neurosci 2: 20.

16. Bu L, Lephart ED (2005) Soy isoflavones modulate the expression of BAD and neuron-specific beta III tubulin in male rat brain. NeurosciLett 385 : 153-157.

17. Trieu VN, Uckun FM (1999) Genistein is neuroprotective in murine models of familial amyotrophic lateral sclerosis and stroke. BiochemBiophys Res Commun 258: 685-688.

18. Setchell KD (2001) Soy isoflavones--benefits and risks from nature's selective estrogen receptor modulators (SERMs). J Am CollNutr 20: 354S-362S.

19. Schreihofer DA, Do KD, Schreihofer AM (2005) High-soy diet decreases infarct size after permanent middle cerebral artery occlusion in female rats. Am J PhysiolRegulIntegr Comp Physiol 289: R103-108.

20. Burguete MC, Torregrosa PA, Asensio G, Fernando J, CastellA, et al. (2006) Dietary phytoestrogens improve stroke outcome after transient focal cerebral ischemia in rats. European Journal of Neuroscience 23: 703-710.

21. Bourque M, Dluzen DE, Di Paolo T (2012) Signaling pathways mediating the neuroprotective effects of sex steroids and SERMs in Parkinson's disease. Front Neuroendocrinol 33: 169-178.

22. Chiang SS, Pan TM (2013) Beneficial effects of phytoestrogens and their metabolites produced by intestinal microflora on bone health. ApplMicrobiolBiotechnol 97: 1489-1500.

23. Newton KM, Buist DS, Keenan NL, Anderson LA, LaCroix AZ (2002) Use of alternative therapies for menopause symptoms: results of a population-based survey. ObstetGynecol 100: 18-25.

24. Lapchak PA, Zhang JH and Noble-Haeusslein LJ (2013) RIGOR guidelines: escalating STAIR and STEPS for effective translational research. Translational stroke research 4:279-285.

25. Khaksari M, Mahmmodi R, Shahrokhi N, Shabani M, Joukar S, et al. (2013) The Effects of Shilajit on Brain Edema, Intracranial Pressure and Neurologic Outcomes following the Traumatic Brain Injury in Rat. Iranian journal of basic medical sciences 16: 858-864.

26. Asl SZ, Khaksari M, Khachki AS, Shahrokhi N, Nourizade S (2013) Contribution of estrogen receptors alpha and beta in the brain response to traumatic brain injury. J Neurosurg 119: 353-361.

27. Consiglio AR, Lucion AB (2000) Technique for collecting cerebrospinal fluid in the cisterna magna of non-anesthetized rats. Brain Res Brain Res Protoc 5: 109-114.

28. King DR, Cohn SM, Proctor KG (2004) Changes in intracranial pressure, coagulation, and neurologic outcome after resuscitation from experimental traumatic brain injury with hetastarch. Surgery 136: 355-363.

29. Feeney DM, Gonzalez A, Law WA (1982) Amphetamine, haloperidol, and experience interact to affect rate of recovery after motor cortex injury. Science 217: 855-857.

30. Monaco CM, Mattiola VV, Folweiler KA, Tay JK, Yelleswarapu NK, et al. (2013) Environmental enrichment promotes robust functional and histological benefits in female rats after controlled cortical impact injury. Experimental neurology 247:410-418. 
31. Sirotkin AV, Harrath AH (2014) Phytoestrogens and their effects. Eur J Pharmacol 741: 230-236.

32. Vaya J, Tamir S (2004) The relation between the chemical structure of flavonoids and their estrogen-like activities. Curr Med Chem 11: 1333-1343.

33. Ballabh P, Braun A, Nedergaard M (2004) The blood-brain barrier: an overview: structure, regulation, and clinical implications. Neurobiol Dis 16: 1-13.

34. Sarkaki AR, Khaksari Haddad M, Soltani Z, Shahrokhi N, Mahmoodi M (2013) Time- and dose-dependent neuroprotective effects of sex steroid hormones on inflammatory cytokines after a traumatic brain injury. J Neurotrauma 30: 47-54.

35. Chen CH, Toung TJ, Sapirstein A, Bhardwaj A (2006) Effect of duration of osmotherapy on blood-brain barrier disruption and regional cerebral edema after experimental stroke. J Cereb Blood Flow Metab 26: 951-958.

36. Ma Q, Huang B, Khatibi N, Rolland W, Suzuki H, Zhang JH and Tang J (2011) PDGFR- $\alpha$ inhibition preserves bloodbrain barrier after intracerebral hemorrhage. Annals of neurology 70:920-931.

37. Yang Y, Estrada EY, Thompson JF, Liu W and Rosenberg GA (2006) Matrix metalloproteinase-mediated disruption of tight junction proteins in cerebral vessels is reversed by synthetic matrix metalloproteinase inhibitor in focal ischemia in rat. Journal of Cerebral Blood Flow \& Metabolism 27:697-709.

38. Ma Y, Lovekamp-Swan T, Bekele W, Dohi A, Schreihofer DA (2013) Hypoxia-inducible factor and vascular endothelial growth factor are targets of dietary soy during acute stroke in female rats. Endocrinology 154: 1589-1597.

39. Gasche Y, Copin J-C, Sugawara T, Fujimura M and Chan PH (2001) Matrix metalloproteinase inhibition prevents oxidative stress-associated bloodbrain barrier disruption after transient focal cerebral ischemia. Journal of Cerebral Blood Flow \& Metabolism 21:1393-1400.

40. Patel HC, Menon DK, Tebbs S, Hawker R, Hutchinson PJ, et al. (2002) Specialist neurocritical care and outcome from head injury. Intensive Care Med 28: 547-553.

41. Soustiel JF, Larisch S (2010) Mitochondrial damage: a target for new therapeutic horizons. Neurotherapeutics 7: 13-21.

42. Lee YW and Lee WH (2008) Protective effects of genistein on proinflammatory pathways in human brain microvascular endothelial cells. The Journal of nutritional biochemistry 19:819-825.

43. Marik P, Chen K, Varon J, Fromm Jr R and Sternbach GL (1999) Management of increased intracranial pressure: a review for clinicians. The Journal of emergency medicine 17:711-719.

44. Dehghan F, KhaksariHadad M, Asadikram G, Najafipour H, Shahrokhi $\mathrm{N}$ (2013) Effect of melatonin on intracranial pressure and brain edema following traumatic brain injury: role of oxidative stresses. Arch Med Res 44: 251-258.

45. Oddo M, Levine JM, Mackenzie L, Frangos S, Feihl F, et al. (2011) Brain hypoxia is associated with short-term outcome after severe traumatic brain injury independently of intracranial hypertension and low cerebral perfusion pressure. Neurosurgery 69:1037-1045.
46. Milde LN, Milde JH, Michenfelder JD (1985) Cerebral functional, metabolic, and hemodynamic effects of etomidate in dogs. Anesthesiology 63: 371-377.

47. Marmarou A (2004) The pathophysiology of brain edema and elevated intracranial pressure. Cleve Clin J Med 71 Suppl 1: S6-8.

48. LANGFITT TW, WEINSTEIN JD, KASSELL NF (1965) CEREBRAL VASOMOTOR PARALYSIS PRODUCED BY INTRACRANIAL HYPERTENSION. Neurology 15: 622-641.

49. Neal CJ, Lee EY, Gyorgy A, Ecklund JM, Agoston DV, et al. (2007) Effect of penetrating brain injury on aquaporin- 4 expression using a rat model. J Neurotrauma 24: 1609-1617.

50. Engelborghs K, Verlooy J, Van Reempts J, Van Deuren B, Van de Ven M, et al. (1998) Temporal changes in intracranial pressure in a modified experimental model of closed head injury. J Neurosurg 89: 796-806.

51. Duckles SP, Krause DN (2007) Cerebrovascular effects of oestrogen: multiplicity of action. ClinExpPharmacolPhysiol 34: 801-808.

52. Patel RP, Boersma BJ, Crawford JH, Hogg N, Kirk M, et al. (2001) Antioxidant mechanisms of isoflavones in lipid systems: paradoxical effects of peroxyl radical scavenging. Free Radical Biology and Medicine 31:1570-1581.

53. Marmarou A (2007) A review of progress in understanding the pathophysiology and treatment of brain edema. Neurosurg Focus 22: E1.

54. Singleton RH, Yan HQ, Fellows-Mayle W and Dixon CE (2010) Resveratrol attenuates behavioral impairments and reduces cortical and hippocampal loss in a rat controlled cortical impact model of traumatic brain injury. Journal of neurotrauma 27:1091-1099.

55. Lovekamp-Swan T, Glendenning M, Schreihofer DA (2007) A high soy diet reduces programmed cell death and enhances bcl-xL expression in experimental stroke. Neuroscience 148: 644-652.

56. Cheatwood JL, Burnet D, Butteiger DN, Banz WJ (2011) Soy protein diet increases skilled forelimb reaching function after stroke in rats. Behav Brain Res 216: 681-684.

57. Ma Y, Sullivan JC and Schreihofer DA (2010) Dietary genistein and equol $\left(4^{\prime}, 7\right.$ isoflavandiol) reduce oxidative stress and protect rats against focal cerebral ischemia. American Journal of Physiology-Regulatory, Integrative and Comparative Physiology 299:R871-R877.

58. Prongay KD, Lewis AD, Hurn PD and Murphy SJ (2010) Dietary soy may not confound acute experimental stroke infarct volume outcomes in ovariectomized female rats. Laboratory animals 44:238-246.

59. Yan EB, Hellewell SC, Bellander B-M, Agyapomaa DA and MorgantiKossmann MC (2011) Post-traumatic hypoxia exacerbates neurological deficit, neuroinflammation and cerebral metabolism in rats with diffuse traumatic brain injury. J Neuroinflammation 8:147-162.

60. Schreihofer DA, Redmond L (2009) Soy phytoestrogens are neuroprotective against stroke-like injury in vitro. Neuroscience 158: 602-609.

61. Zhao L, Mao Z and Brinton RD (2009) A select combination of clinically relevant phytoestrogens enhances estrogen receptor $\mathrm{I}^{2}$-binding selectivity and neuroprotective activities in vitro and in vivo. Endocrinology 150:770-783. 